\title{
Prevalence of Type 2 Diabetes Mellitus among Kuwaiti Children and Adolescents
}

\author{
Mohamed A.A. Moussa ${ }^{a}$ Mayra Alsaeid $^{b}$ Nabila Abdellac ${ }^{c}$ Thanaa M.K. Refai ${ }^{d}$ f \\ Nashami Al-Sheikh ${ }^{\mathrm{e}}$ Joseph E. Gomez ${ }^{\mathrm{a}}$ \\ Departments of a Community Medicine and Behavioural Sciences, ${ }^{b}$ Paediatrics, and ${ }^{\mathrm{c}}$ Medicine, \\ Faculty of Medicine, Kuwait University, d Department of Clinical Pathology, Al-Amiri Hospital, and \\ e Department of School Health, Ministry of Health, Kuwait; ${ }^{\dagger}$ Ain Shams University Hospital, Cairo, Egypt
}

\section{Key Words}

Type 2 diabetes, prevalence $\cdot$ Family history of type 2

diabetes $\cdot$ Kuwaiti children and adolescents

\begin{abstract}
Objectives: To determine the prevalence of type 2 diabetes among 6- to 18-year-old Kuwaiti children. Subjects and Methods: Children with type 2 diabetes were identified at 182 schools (50 primary, 63 intermediate, and 69 secondary) randomly selected using the 2000/2001 educational districts' registers as a sampling frame. Prevalence rates were adjusted to the 2002 Kuwaiti population. Diagnosis of type 2 diabetes was based on the World Health Organization and the American Diabetes Association criteria. Results: Type 2 diabetes was identified in 45 of the 128,918 children surveyed, thereby giving an overall prevalence of 34.9 per 100,000 [95\% confidence interval (Cl) 24.7-45.1]. There was a significant difference in prevalence between males (47.3, $95 \% \mathrm{Cl} 28.7-65.8)$ and females $(26.3,95 \% \mathrm{Cl} 14.8-37.8)$ at $\mathrm{p}=$ 0.05 and a significant trend for an increase in prevalence of type 2 diabetes with age $(p=0.026)$. The overall age-adjusted prevalence rate in the 2002 Kuwaiti population was 33.2 (95\% Cl 26.6-39.9), 41.6 (95\% Cl 31.2-52.0) in male and 24.6 $(95 \% \mathrm{Cl} 16.4-32.7)$ in female children; the difference was sig-
\end{abstract}

nificant at $p=0.013$. There was no significant difference in prevalence between regions. Children with type 2 diabetes had a significantly higher frequency $(51.1 \%)$ of a positive family history of diabetes than children of a similar age without type 2 diabetes $(22.2 \%)(p=0.004)$. Conclusion: The prevalence of type 2 diabetes in adult Kuwaitis is spreading to children and adolescents, making it an emergency public health problem. Efforts need to be initiated to address prevention strategies of type 2 diabetes in youth.

Copyright $\odot 2008$ S. Karger AG, Base

\section{Introduction}

Type 2 diabetes has been considered a disease of adult and older individuals and not a pediatric condition. Type 1 diabetes was the only type of diabetes believed to be prevalent in youth. However, over the last 2 decades, type 2 diabetes has been emerging as a public health problem in children and adolescents [1-4].

Type 2 diabetes is a polygenic condition in which insulin is not essential for survival of the patient, although it may be required for adequate metabolic control. It has a strong hereditary component and results from a combination of insulin resistance, increased hepatic glucose

\section{KARGER}

Fax +4161306 1234

E-Mail karger@karger.ch

www.karger.com
(C) 2008 S. Karger AG, Basel

$1011-7571 / 08 / 0174-0270 \$ 24.50 / 0$

Accessible online at:

www.karger.com/mpp
Mohamed A.A. Moussa

Department of Community Medicine and Behavioural Sciences Faculty of Medicine, Health Sciences Centre, Kuwait University PO Box 24923, Safat, 13110 (Kuwait)

Tel. +965 5319 485, Fax +965 5338 948, E-Mail amoussa@hsc.edu.kw 
output and progressive decline of glucose-stimulated insulin secretion. Unlike type 1 diabetes, where there is an absolute deficiency of insulin secretion, patients with type 2 diabetes have insulin secretory capacity but insulin levels are inadequate to overcome the concomitant peripheral insulin resistance, causing the development of hyperglycemia [5].

Because there are geographical and ethnic variations in the prevalence of type 2 diabetes, it is important to study the disease in various populations. Epidemiological studies have shown a high prevalence of type 2 diabetes among the adult Arab population of the Gulf countries [6,7]. In the United Arab Emirates, type 2 diabetes is estimated to be about $20 \%$ of the adult population [8]. In a study on childhood and adolescent diabetes mellitus in Al-Ain, United Arab Emirates, the authors observed an emergence of type 2 diabetes in their pediatric population. Of 96 children newly diagnosed with diabetes mellitus between January 1990 to December 2001, 11 were identified as type 2 diabetes [9].

In Kuwait, a high prevalence of type 2 diabetes among adults has been reported [10]; however, the prevalence of type 2 diabetes in the pediatric population is unknown. Therefore, the aim of the present study was to determine the prevalence of type 2 diabetes among 6- to 18 -year-old Kuwaiti children.

\section{Subjects and Methods}

\section{Study Population and Sampling Plan}

Children aged 6-18 years with type 2 diabetes were identified at 182 schools (50 primary, 63 intermediate, and 69 secondary) in Kuwait during the study period October 2000 to September 2002. In each governorate (Capital, Hawally, Farwaniya and Ahmadi) there is an educational district which includes male and female schools for the three levels of education: primary, intermediate and secondary. The 2000/2001 educational districts' registers were used as sampling frames. The number of schools was randomly selected from these sampling frames proportional to the number of schools in each district according to gender and level of education. The number of schools included represented $48.4 \%$ of the total number of schools at each study level. The total number of children surveyed was 128,918 , i.e. 52,864 males and 76,054 females.

Children start primary, intermediate and secondary education at age 6, 10, and 14 years, respectively. Each level lasts 4 years. There are separate schools for male and female children. The primary data source was the medical records maintained by school nurses for all children with type 2 diabetes for use in emergencies. These medical records are created and updated annually by the schools' physicians, who undertake medical checkups for all school children at the beginning of each year. Diagnosis of type 2 diabetes was made according to the World Health Organization
[11] and the American Diabetes Association $[12,13]$ criteria which stipulate that for epidemiological studies, estimates of diabetes prevalence are based on fasting plasma glucose of $\geq 7.0 \mathrm{mmol} / \mathrm{l}$. Type 2 diabetes was further confirmed by fasting plasma glucose of $\geq 7.0 \mathrm{mmol} / \mathrm{l}$. The secondary data source was independent of the primary data source and was obtained by asking all children and parents about the presence of type 2 diabetes. In order to compare the frequency of a family history of diabetes in the affected children, a group of healthy classmates without type 2 diabetes was selected. The two groups of children, with and without diabetes, were similar in age, gender, and ethnic background.

\section{Statistical Methods}

Age- and sex-specific prevalence rates (per 100,000) for type 2 diabetes were computed by relating the number of accumulated previous and newly diagnosed diabetic children up to the study year 2002 to the number of children at the schools from which children with diabetes were identified. Prevalence rates were adjusted to the 2002 Kuwaiti population to estimate the number of children with diabetes at the ages that were studied in the population. The population data were obtained from the 2002 report of the Public Authority for Civil Information, Kuwait. The 95\% confidence intervals (CIs) were estimated and prevalence rates were compared assuming a Poisson distribution [14]. The $\chi^{2}$ test was used to assess the significance of the difference between the proportion of a positive family history of diabetes in children with and without diabetes. The $\chi^{2}$ test for linear trend was used to ascertain the increase in the type 2 diabetes prevalence rate as age increases.

\section{Results}

The age- and sex-specific prevalence rates of type 2 diabetes in Kuwaiti children and adolescents aged 6-18 years as of 2002 are presented in table 1 . There were 45 children with type 2 diabetes identified from the surveyed number of 128,918 school children aged $6-18$ years, giving an overall prevalence of 34.9 per 100,000 (95\% CI 24.7-45.1). Of the 45 type 2 diabetic children, 25 were male and 20 were female; the male/female ratio was 1.25:1. The prevalence among males was $47.3 / 100,000$ (95\% CI 28.7-65.8), which is higher than that in females (26.3, 95\% CI 14.8-37.8) and the difference was significant $(\mathrm{p}=0.05)$. The male/female ratio in prevalence was 1.8:1. There was a significant trend of an increase in prevalence of type 2 diabetes with age overall and in males $\left(\chi^{2}\right.$ for linear trend, $p=0.026$ and 0.05 overall and in males, respectively). The prevalence rates for the age groups 6-9 (primary), 10-13 (intermediate), and 14-18 (secondary) in males were 17.3 (95\% CI 0-41.4), 45.3 (95\% CI 15.774.8), and 65.2 (95\% CI 31.0-99.3) per 100,000, respectively. The corresponding prevalence rates for females were 17.2 (95\% CI 0-36.6), 20.4 (95\% CI 2.5-38.4), and 
Table 1. Age- and sex-specific prevalence rates (per 100,000) of type 2 diabetes in Kuwaiti children and adolescents aged $6-18$ years

\begin{tabular}{|c|c|c|c|c|c|c|}
\hline \multirow[t]{2}{*}{ Age group, years } & \multicolumn{2}{|c|}{ Males } & \multicolumn{2}{|c|}{ Females } & \multicolumn{2}{|c|}{ Total } \\
\hline & $\mathrm{n}$ & prevalence rate & $\mathrm{n}$ & prevalence rate & $\mathrm{n}$ & prevalence rate \\
\hline $6-9$ (primary) & 2 & $17.3(0-41.4)$ & 3 & $17.2(0-36.6)$ & 5 & $17.2(2.1-32.3)$ \\
\hline 10-13 (intermediate) & 9 & $45.3(15.7-74.8)$ & 5 & $20.4(2.5-38.4)$ & 14 & $31.6(15.0-48.1)$ \\
\hline 14-18 (secondary) & 14 & $65.2(31.0-99.3)$ & 12 & $35.2(15.3-55.1)$ & 26 & $46.8(28.8-64.8)$ \\
\hline 6-18 (all) & 25 & $47.3(28.7-65.8)$ & 20 & $26.3(14.8-37.8)$ & 45 & $34.9(24.7-45.1)$ \\
\hline
\end{tabular}

$\mathrm{n}=$ Identified number of children with type 2 diabetes. Figures in parentheses indicate 95\% CIs.

Table 2. Age- and sex-adjusted prevalence rates (per 100,000) of type 2 diabetes in the Kuwaiti 2002 population

\begin{tabular}{|c|c|c|c|c|c|c|}
\hline \multirow[t]{2}{*}{ Age group, years } & \multicolumn{2}{|c|}{ Males } & \multicolumn{2}{|c|}{ Females } & \multicolumn{2}{|c|}{ Total } \\
\hline & $\mathrm{n}$ & adjusted prevalence rate & $\mathrm{n}$ & adjusted prevalence rate & $\mathrm{n}$ & adjusted prevalence rate \\
\hline 6-18 (all) & 61 & $41.6(31.2-52.0)$ & 35 & $24.6(16.4-32.7)$ & 96 & $33.2(26.6-39.9)$ \\
\hline
\end{tabular}

$\mathrm{n}=$ Estimated number of children with type 2 diabetes in the Kuwaiti 2002 population. Figures in parentheses indicate $95 \%$ CIs.

35.2 (95\% CI 15.3-55.1) per 100,000, respectively. In combined male and female prevalence rates, the highest prevalence was for age 14-18 (46.8), while the lowest was for age 6-9 (17.2) per 100,000; the difference was significant $(\mathrm{p}=0.04)$.

Prevalence rates of type 2 diabetes were adjusted by age and sex to the 2002 Kuwaiti population. The number of 6 - to 18-year-old children with type 2 diabetes in the 2002 population was estimated to be 96 in a population of 289,044, resulting in an overall age-adjusted prevalence rate of 33.2 (95\% CI 26.6-39.9) per 100,000 population. The age-adjusted prevalence rate was $41.6(95 \% \mathrm{CI}$ $31.2-52.0)$ in males and 24.6 (95\% CI 16.4-32.7) in females in the 2002 Kuwaiti population; the difference was significant ( $\mathrm{p}=0.013$; table 2$)$.

There was no significant difference in prevalence between regions. Children with type 2 diabetes had a significantly higher frequency (51.1\%) of a positive family history of diabetes than children of a similar age (22.2\%) without type 2 diabetes $(\mathrm{p}=0.004)$. Similarly, children with type 2 diabetes had a significantly higher frequency (42.2\%) of a positive family history of type 1 diabetes than children without type 2 diabetes $(8.9 \%)(\mathrm{p}=0.001$; table 3).
The mean age \pm standard deviation of children with type 2 diabetes was $14.2 \pm 3.0$ years in the whole group; $14.3 \pm 2.8$ and $14.1 \pm 3.4$ years in males and females, respectively. In both sexes, the onset of type 2 diabetes occurred in 5 (11.1\%) of children at the age of 6-9 years, in $14(31.1 \%)$ at the age of $10-13$, and in $26(57.8 \%)$ at the age of $14-18$ years.

\section{Discussion}

The present study focused on determining the prevalence of type 2 diabetes among Kuwaiti children and adolescents while previously emphasis has been placed on the study of type 2 diabetes in adulthood [10]. Type 2 diabetes in children was considered as a rarity until recently as there are no population-based prevalence data for type 2 diabetes in children except for North American Indians [15].

The prevalence of type 2 diabetes varies among different populations. Type 2 diabetes in children and adolescents, which is emerging as a global epidemic, was first described in Pima Indian adolescents of Arizona (USA) in 1979 [16] and subsequently reported among various 
Table 3. Family history of diabetes mellitus in Kuwaiti children with type 2 diabetes and in children without type 2 diabetes

\begin{tabular}{|c|c|c|c|c|}
\hline & \multicolumn{2}{|c|}{$\begin{array}{l}\text { Family history of type } 1 \\
\text { diabetes }\end{array}$} & \multicolumn{2}{|c|}{$\begin{array}{l}\text { Family history of type } 1 \text { or } 2 \\
\text { diabetes }\end{array}$} \\
\hline & $\mathrm{n}$ & $\%$ & $\mathrm{n}$ & $\%$ \\
\hline \multicolumn{5}{|l|}{ Father only } \\
\hline Children with type 2 diabetes & 12 & 26.7 & 16 & 35.6 \\
\hline Children without type 2 diabetes & 2 & 4.4 & 7 & 15.6 \\
\hline $\mathrm{p}$ value & 0.007 & & 0.030 & \\
\hline \multicolumn{5}{|l|}{ Mother only } \\
\hline Children with type 2 diabetes & 8 & 17.8 & 9 & 20.0 \\
\hline Children without type 2 diabetes & 2 & 4.4 & 4 & 8.9 \\
\hline $\mathrm{p}$ value & 0.09 & & 0.134 & \\
\hline \multicolumn{5}{|l|}{ Father or mother } \\
\hline Children with type 2 diabetes & 19 & 42.2 & 23 & 51.1 \\
\hline Children without type 2 diabetes & 4 & 8.9 & 10 & 22.2 \\
\hline $\mathrm{p}$ value & 0.001 & & 0.004 & \\
\hline
\end{tabular}

minority non-Caucasian ethnic groups in the USA, Canada, Australia, New Zealand and among children from Japan, Hong Kong, Libya and Bangladesh [17] as well as in Asian and Arab children from the UK [1]. Among Japanese school children, the prevalence of type 2 diabetes has increased in 20 years, from 2 to 76 per 100,000 individuals [18]. A study in Libya [19] revealed an incidence of type 2 diabetes ( $0-34$ years at onset) of 19.6 and 35.3 per 100,000 individuals for males and females, respectively. In the present study, the prevalence rate for type 2 diabetes was 34.9 per 100,000 children aged $6-18$ years and accounts for $11.5 \%$ of all school children presenting with diabetes. The prevalence of type 2 diabetes in Native Indian children in Manitoba was 53 per 100,000 children 1-14 years of age. In general, type 2 diabetes seems to account for $8-45 \%$ of all youth presenting with diabetes mellitus, depending on geographical location and racial composition [5]. It seems that in populations with a high prevalence of type 2 diabetes in adults, there may be a spread of the disease to its pediatric population as reported in Japan [20].

A feature of the pattern of prevalence of type 2 diabetes in this study was the high percentage of children in the age group 14-18 years (57.8\%), as the prevalence rate in this group was the highest $(46.8$ per 100,000$)$ as previously reported for children during mid-puberty [5]. This is most likely due to the temporary evolution of insulin resistance during pubertal maturation. This insulin re- sistance of puberty is manifested by a reduction of approximately $30 \%$ of in vivo insulin action in adolescents compared with prepubertal children or adults [21, 22]. Puberty is associated with transient insulin resistance and hyperinsulinemia compared with prepuberty and young adulthood. Pubertal insulin resistance is attributed to increased growth hormone secretion during puberty and not to sex hormone secretion [23].

Our data showed that the prevalence of type 2 diabetes was higher in males than females, overall or at any age group. This result is inconsistent with other studies [18, 19] which concluded that female children and adolescents were more susceptible to the risk of developing type 2 diabetes. However, in a Libyan study, children younger than 15 years of age of both sexes were shown to have a similar level of type 2 diabetes prevalence [19]. Our result may be explained by the fact that none of the 20 females with type 2 diabetes had conditions associated with insulin resistance, such as polycystic ovary syndrome, which is considered as a risk factor for type 2 diabetes in adolescent females [24]. In the meantime, the present study did not show a difference in prevalence between regions, most probably because Kuwait is a small country with no climatic, geographical or environmental variations between the governorates.

The present study showed a remarkably high frequency of a positive family history of type 1 diabetes among the parents of children with type 2 diabetes as well as in 
the background population. That $42.2 \%$ of children with type 2 diabetes had a family history of type 1 diabetes is consistent with the notion that diabetes etiology involves exposure to environmental factors in genetically susceptible individuals. Children with parents having diabetes are at increased risk of developing the disease. The familial disposition to diabetes in children could be related to either impaired insulin action or impaired insulin secretion as a risk factor. Prepubertal healthy children with a family history of type 2 diabetes have nearly $25 \%$ lower in vivo insulin sensitivity than age- and body composition-matched children without a family history of type 2 diabetes [25]. Thus, this familial risk of lower insulin sensitivity when compounded with adverse environmental conditions of high energy intake and low energy expenditure may ultimately express itself in type 2 diabetes.

The frequency of a positive family history of diabetes among parents in the population without type 2 diabetes is different from other populations in being almost one half $(22.2 \%)$ of the frequency of a positive family history in affected children with type 2 diabetes (51.1\%). The high frequency of a family history of type 1 diabetes (42.2\%) in parents of children with type 2 diabetes supports the proposition that a family history of type 1 diabetes is associated with a greater frequency of type 2 diabetes and vice versa. The relationship between type 1 and type 2 diabetes may suggest a genetic association between the two diseases. In addition, similar environmental risk determinants for type 1 and type 2 diabetes may also explain the association.

The age of onset of type 2 diabetes is steadily decreasing as a consequence of rapid modernization with major lifestyle changes resulting in childhood obesity, insulin resistance inducing glucose intolerance and premature atherosclerosis. This has an impact on clinical and economic aspects of diabetic care in childhood and adolescence.

In Kuwait, the overall prevalence rate of type 2 diabetes among adults was reported as $7.6 \%$ in 1995 [26]. In another study [10], the overall prevalence rate of type 2 diabetes among Kuwaiti adults aged $\geq 20$ years was $14.8 \%$ and presented at a relatively young age. This indicates that changes in environmental factors may be causing a rapid rise in the prevalence of type 2 diabetes. Obesity is now the most common nutritional disease of children [27], and its prevalence continues to escalate. Of Kuwaiti children, $26.5 \%$ are obese, which is higher than the prevalence reported in other populations [27]. Despite a strong genetic component in obesity, its increasing prevalence is widely ascribed to environmental factors that promote the expression of obesity. The negative impacts of obesity on insulin sensitivity and disturbances in the pathogenesis of glucose metabolism are evident early in childhood. Moreover, the amount of visceral fat is directly correlated with insulinemia and negatively with insulin sensitivity [15]. Accordingly, obesity in children appears to be a major risk factor for type 2 diabetes [15]. The high prevalence of obesity among Kuwaiti children has a role in accounting for the high prevalence of type 2 diabetes. In a population like Kuwait with a high prevalence of type 2 diabetes in adults, there may be a spread of the disease to its pediatric population. Kuwaitis constitute a young population (52.5\% of the 2001 population is younger than 20 years) and have a high crude birthrate (30.9/1,000 population) [28]. Consequently, if the prevalence of type 2 diabetes continues to increase, the number of children and adolescents with the disease will multiply rapidly.

\section{Conclusion}

Kuwait is among the populations with the highest prevalence of type 2 diabetes in adults, which is spreading to children and adolescents. Type 2 diabetes is no longer a disease of adults only. Over the last decade, there has been an increase in the number of children and adolescents with type 2 diabetes, making it an emerging and serious public health problem. Efforts need to be initiated to address treatment and prevention strategies of type 2 diabetes in youth.

\section{Acknowledgement}

This study was supported by the Kuwait University research grant number MC046.

References $>1$ Ehtisham S, Barrett TG, Shaw NJ: Type 2 diabetes mellitus in UK children - An emerging problem. Diabet Med 2000;17:867-871.

2 Aye T, Levitsky LL: Type 2 diabetes: an epidemic disease in childhood. Curr Opin Pediatr 2003;15:411-415.

> 3 Rosenbloom AL, Joe JR, Young RS, Winter WE: Emerging epidemic of type 2 diabetes in youth. Diabetes Care 1999;22:345-354.

4 Pontiroli AE: Type 2 diabetes mellitus is becoming the most common type of diabetes in school children. Acta Diabetol 2004;41:8590 . 
5 Libman I, Arslanian S: Type 2 diabetes in childhood: the American perspective. Horm Res 2003;59(suppl 1):69-76.

-6 Asfour MG, Lambourne A, Soliman A, AlBehlani S, Al-Asfoor D, Bold A, Mahtab H, King H: High prevalence of diabetes mellitus and impaired glucose tolerance in the Sultanate of Oman: results of the national survey. Diabet Med 1995;12:1122-1125.

7 Al-Nuaim R: Prevalence of glucose tolerance in urban and rural communities in Saudi Arabia. Diabet Med 1997;14:595-602.

8 International Diabetes Federation: Diabetes e-Atlas. Available at: http://www.eatlas/idf/ org (accessed November 26, 2006).

-9 Punnose J, Agarwal MM, El Khadir A, Devadas K, Mugamer IT: Childhood and adolescent diabetes mellitus in Arabs residing in the United Arab Emirates. Diabetes Res Clin Pract 2002;55:29-33.

10 Abdella N, Khogali M, Al-Ali S, Gumaa K, Bajaj J: Known type 2 diabetes mellitus among the Kuwaiti population: a prevalence study. Acta Diabetol 1996;33:145-149.

11 World Health Organization: Diabetes Mellitus - Report of a WHO Study Group. Geneva, World Health Organization, 1985, Technical Report Series 727.

12 American Diabetes Association: Report of the Expert Committee on the Diagnosis and Classification of Diabetes Mellitus. Diabetes Care 1998;21(suppl 1):S5-S17.
13 American Diabetes Association: Type 2 diabetes in children and adolescents. Diabetes Care 2000;23:381-389.

14 Armitage P, Berry G: Statistical Methods in Medical Research. Oxford, Blackwell, 1987.

15 Arslanian S: Type 2 diabetes in children: clinical aspects and risk factors. Horm Res 2002;57(suppl 1):19-28.

16 Savage PJ, Bennett PH, Senter RG, Miller M: High prevalence of diabetes in young Pima Indians: evidence of phenotypic variation in a genetically isolated population. Diabetes 1979;28:937-942.

17 Fagot-Campagna A: Emergence of type 2 diabetes mellitus in children-Epidemiological evidence. J Pediatr Endocrinol Metab 2000; 13(suppl 6):1395-1402.

18 Kitagawa T, Owada M, Urakami T, Tajima N: Epidemiology of type 1 (insulin-dependent) and type 2 (non-insulin-dependent) diabetes mellitus in Japanese children. Diabetes Res Clin Pract 1994;24(suppl):S7-S13.

19 Kadiki OA, Reddy MR, Marzouk AA: Incidence of insulin-dependent diabetes (IDDM) and non-insulin-dependent diabetes (NIDDM) (0-34 years at onset) in Benghazi, Libya. Diabetes Res Clin Pract 1996;32:165173.

20 Kitagawa T, Owada M, Urakami T, Yamanchi K: Increased incidence of non-insulin dependent diabetes mellitus among Japanese school children correlates with an increased intake of animal protein and fat. Clin Pediatr 1998;37:111-116.
21 Scott CR, Smith JM, Cradock MM, Pihoker C: Characteristics of youth-onset non-insulin-dependent diabetes mellitus and insulindependent diabetes mellitus at diagnosis. Pediatrics 1997;100:84-91.

22 Amiel S, Sherwin S, Simonson D, Lauritano A, Tamborlane W: Impaired insulin action in puberty: a contributing factor to poor glycemic control in adolescents with diabetes. N Engl J Med 1986;315:215-219.

23 Arslanian S: Type 2 diabetes mellitus in children: pathophysiology and risk factors. J Pediatr Endocrinol Metab 2000;13:1385-1394

24 Lewy VD, Danadian K, Witchel SF, Arslanian S: Early metabolic abnormalities in adolescent girls with polycystic ovary syndrome. J Pediatr 2001;138:38-44.

25 Danadian K, Balasekaran G, Lewy V, Meza M, Robertson R, Arslanian SA: Insulin sensitivity in African-American children with and without family history of type 2 diabetes. Diabetes Care 1999;22:1325-1329.

26 Abdella NA, Khogali MM, Salman AD, Ghuneimi SA, Bajaj JS: Pattern of non-insulin dependent diabetes mellitus in Kuwait. Diabetes Res Clin Pract 1995;9:129-136.

27 Moussa MAA, Shaltout AA, Al-Sheikh N, Agha N: Prevalence of obesity among 6- to 13-year old Kuwaiti children. Med Princ Pract 1999;8:272-280.

28 Vital and Health Statistics: Health Kuwait. Kuwait, Ministry of Health, 2001, ed 38, pp 43-44. 